\title{
HIDDEN MARKOV MODEL APPLICATION TO TRANSFER THE TRADER ONLINE FOREX BROKERS
}

\author{
Farida Suharleni'1), Agus Widodo2), Endang Wahyu H.3) \\ ${ }^{1}$ Magister Student of Mathematics Department, Brawijaya University, Malang \\ 2,3 Lecturer of Mathematics Department, Brawijaya University, Malang \\ ${ }^{1}$ email: farida_jelita@yahoo.co.id
}

\begin{abstract}
Hidden Markov Model is elaboration of Markov chain, which is applicable to cases that can't directly observe. In this research, Hidden Markov Model is used to know trader's transition to broker forex online. In Hidden Markov Model, observed state is observable part and hidden state is hidden part. Hidden Markov Model allows modeling system that contains interrelated observed state and hidden state. As observed state in trader's transition to broker forex online is category 1, category 2, category 3, category 4 , category 5 by condition of every broker forex online, whereas as hidden state is broker forex online Marketiva, Masterforex, Instaforex, FBS and Others. First step on application of Hidden Markov Model in this research is making construction model $\lambda=(\boldsymbol{\pi}, \boldsymbol{A}, \boldsymbol{B})$ by making a probability of transition matrix $(\boldsymbol{A})$ from every broker forex online. Next step is making a probability of observation matrix $(\boldsymbol{B})$ by making conditional probability of five categories, that is category 1 , category 2 , category 3 , category 4 , category 5 by condition of every broker forex online and also need to determine an initial state probability $(\boldsymbol{\pi})$ from every broker forex online. The last step is using Viterbi algorithm to find hidden state sequences that is broker forex online sequences which is the most possible based on model $\lambda=(\boldsymbol{\pi}, \boldsymbol{A}, \boldsymbol{B})$ and observed state that is the five categories. Application of Hidden Markov Model is done by making program with Viterbi algorithm using Delphi 7.0 software with observed state based on simulation data. Example: By the number of observation $T=5$ and observed state sequences $O=(2,4,3,5,1)$ is found hidden state sequences which the most possible with observed state $O$ as following : $X=\left(X_{1}=4, X_{2}=2, X_{3}=1, X_{4}=5, X_{5}=3\right)$ where $X_{1}=$ FBS, $X_{2}=$ Masterforex, $X_{3}=$ Marketiva, $X_{4}=$ Others, and $X_{5}=$ Instaforex.
\end{abstract}

Keywords: Hidden Markov Model, Trader, Broker forex online

\section{INTRODUCTION}

Electronic technology-based life was intense, vigorous today. Investment world to feel the impact of the development of electronic technology. For example: investing through forex (foreign exchange) or foreign currency exchange is taking advantage of the electronic technology better known as forex online.

This online forex trading brokerage services utilizing the so-called online forex broker. By definition, online forex broker is a party that can be a company, individual or agency in which he is established or function as an intermediary to bridge or reconcile between the buyer and seller. The presence of online forex broker is easier for traders to trade forex online. However, along with the increasing number of online forex brokers, the greater the opportunity for traders to move from one broker to another broker.

\section{Limitation of the research problem}

Extent of the problem in this research is:

1. The data used are primary data, the survey data using questionnaires. Respondents in this study are online forex traders in Indonesia.

2. Five kinds of online forex brokers that will be examined in this study is Marketiva, Masterforex, Instaforex, FBS, and the fifth one is a collection of other online forex brokers (others).

\section{The purpose of research}

Along with the formulation of the problem, the objectives of this study were:

1. Knowing the Hidden Markov Model construction for traders shift towards online forex broker.

2. Implementing a Hidden Markov Model construction is on the software using Delphi 7.0 software.

\section{LITERATURE REVIEW}

\section{Chance}

Opportunity is a value between 0 and 1 that describes the size of the opportunity for the emergence of a specific event on a specific condition. Other terms of the probability opportunities. Odds of an event that must happen or opportunities certainty is 1 , denoted $P(S)=1$, while odds improbable events or opportunities impossibility is 0 , denoted. $P(\varnothing)=0$ In full, the probability of an event $\mathrm{A}$, denoted $\mathrm{P}(\mathrm{A})$, are: $0 \leq P(A) \leq 1$. (Nugroho, 2008) 


\section{Conditional Genesis}

Conditional Genesis is an event that will occur with other conditions incident has occurred. Provided A and B are two events in the sample space, chances conditional $B$ if event $A$ is known or has been denoted by $P(B \mid A)$. Thus, it can be denoted: : $P(B \mid A)$, and read: "The odds of a $B$, if A has occurred" or "Chance $B$, if $A$ is known to opportunity", where

$$
P(B \mid A)=\frac{P(A \cap B)}{P(A)}
$$

with $P(A)>0$. (Walpole, 1995)

\section{Stochastic Processes}

The term stochastic processes are widely used for events related to the time-oriented observation. Stochastic process is a family of random variables $\{X(t), t \in T\}$ where $\mathrm{t}$ is the parameter "Time" of the set T. T is a parameter of "time" that has discrete or continuous nature. That is, if, then the stochastic process is parameterized "timing" discrete and usually denoted. If $T=\{0,1,2,3 \ldots\}$ then the stochastic process is parameterized "time" is continuous and is usually denoted by $\left\{X_{n}, n=0,1,2,3 \ldots.\right\}$.

All possible prices happened $t$ random variable is called the state space "state" which is denoted by Q. State space "state" is called discrete if finite or infinite countable, otherwise state space "state" is called continuous if the interval of the real line containing.

For example, the number of messages that arrive in the time period from 0 to $t$ is $\{N(t), t \geq 0\} \quad$ parameterized "time" and continuous state space "state" discrete.

One of the stochastic process is Markov chain models which have the property that the stochastic behavior in the future depends only on the time or the current situation and do not depend on the state of the past. (Lester, 2009)

\section{Markov Chain}

\section{Basic Concepts of Markov Chain}

Markov chain model was developed by a Russian expert AA Markov in 1906. Markov chain is a stochastic process that has the property that if the value $X_{t}$ is known, then $X_{s}$ where $s>t$, is not affected by $X_{j}$. where $t>j$.The definition means that the phenomenon of the future is only affected by the phenomenon of the present, and not influenced by the past. Mathematically, the Markov chain can are expressed as follows:

$$
\begin{aligned}
P\left(X_{t+1}\right. & \left.=j \mid X_{1}, X_{2}, \cdots, X_{t}=i\right) \\
& =P\left(X_{t+1}=j \mid X_{t}=i\right),
\end{aligned}
$$

where $i, j \in Q$ and $Q=\left\{q_{1, \cdots,} q_{N}\right\}$ are the set of possible state and $t \in T$. (Lester, 2009)

\section{Early Opportunity Matrix ( $\pi$ )}

Value of early chances are $P\left(X_{0}=q_{i}\right)=\pi_{i}$, so that for every $i, \pi_{i} \geq 0, N \mathrm{~N}$ is the number of state and $\sum_{i=1}^{N} \pi_{i}=1$.

Initially Opportunities outlined in the matrix is called a row vector as the contents of the existing opportunities in the beginning it was a chance that symbolized $\pi_{i}$ so,

$$
\boldsymbol{\pi}=\left[\begin{array}{llll}
\pi_{1} \pi_{2} \pi_{3} & \cdots & \pi_{N}
\end{array}\right] \quad \text { (Hidayanto, 2009) }
$$

\section{Opportunity Transition Matrix (A)}

Opportunities outlined in the transition matrix of transitional opportunities dimension $\mathrm{N}$ $\mathrm{x} \mathrm{N}$. The matrix A is formed by $a_{i j}$ the transition from state $\mathrm{i}$ opportunity to state $\mathrm{j}$ in one step can be denoted:

$$
a_{i j}=P\left(X_{t+1}=j \mid X_{t}=i\right)
$$

A matrix formed by the above is called the transition matrix of the Markov chain opportunities. The shape of the transition matrix A the following opportunities:

$$
\boldsymbol{A}=\left[\begin{array}{cccc}
a_{11} & a_{12} & \cdots & a_{1 N} \\
a_{21} & a_{22} & \cdots & a_{2 N} \\
\cdots & \cdots & \ddots & \cdots \\
a_{N 1} & a_{N 2} & \cdots & a_{N N}
\end{array}\right] \text { new state }
$$

for $\mathrm{i}=1,2, \ldots, \mathrm{N}$ and $\mathrm{j}=1,2, \ldots \mathrm{N}$.

In the transition matrix of the Markov chain opportunities has traits - traits that entry on each line numbered one. In other words every i holds: $\sum_{j=1}^{N} a_{i j}=1, a_{i j} \geq 0$. (Sumarminingsih, 2006)

\section{Hidden Markov Model (HMM)}

Hidden Markov models or Hidden Markov Model (HMM) is a statistical model of a system that assumed a Markov process with unknown parameters. The problem is to determine the hidden parameters (hidden) of the parameters that can be observed (observed). Specified parameters can then be used for further analysis. A Hidden Markov Model can be considered as a dynamic Bayesian Network simplest. In the general Markov model, its state can be observed directly, therefore the transition state the opportunity to be the only parameter. In the Hidden Markov Model, statenya can't be observed directly, but can be observed are the parameters that are affected by the state. Each state has a probability distribution that may arise, therefore the output sequence produced by the Hidden Markov Model provide some more information about the sequence of states.

(http://www.wikipedia.com)

\section{Definition of HMM}

Hidden Markov Model (HMM) is a statistical tool that is used to model the rows that have a time span between the data with each other data. The data will be analyzed using the HMM data with Markov process. (Evans, 2003) 


\section{Elements of HMM}

HMM can be defined as accumulated's five elements (N, M, $\boldsymbol{\pi}, \mathrm{A}, \mathrm{B})$. If considered $\boldsymbol{\lambda}=(\boldsymbol{\pi}, \boldsymbol{A}, \boldsymbol{B})$ the HMM has a certain element of $\mathrm{N}$ and $M$. The explanation will these elements are: 1. The matrix of transition opportunities (A)

$$
\boldsymbol{A}=\left\{a_{i j}\right\}, a_{i j}=P\left(X_{t+1}=q_{j} \mid X_{t}=q_{i}\right) 3
$$

For each $1 \leq i, j \leq N$.

2. Matrix chance observation (B)

$\boldsymbol{B}=\left\{b_{i}\left(v_{k}\right)\right\}$ an output matrix opportunity with $b_{i}\left(v_{k}\right)$ a chance observation at time $\mathrm{t}$ categorized $v_{k}$ the condition state at time $\mathrm{t}$ is the state $q_{i}$. Can be written:

$$
b_{i}\left(v_{k}\right)=P\left(O_{t}=v_{k} \mid X_{t}=q_{i}\right) \text {, }
$$

$$
1 \leq i \leq N, 1 \leq k \leq M
$$

where the observation matrix mem-possess opportunity features - features that entry on each line of a. In other words:

$$
\sum_{k=1}^{M} b_{i}\left(v_{k}\right)=1 \quad, i=1,2,3 \ldots \ldots, N
$$

3. Matrix opportunities early $(\pi)$ $\boldsymbol{\pi}=\left\{\pi_{i}\right\}, \pi_{i}=P\left(X_{o}=q_{i}\right)$ For $i=1,2,3 \ldots \ldots, N, \pi_{i} \geq 0$

4. $\mathrm{N}$, the number of hidden state. Denote the set is limited to state that it probably is. $\boldsymbol{Q}=\left\{q_{1}, q_{2}, \ldots, q_{N}\right\}$.

5. $M$, the number of observed states can be observed. Denote the set is limited to observation is probably $\boldsymbol{V}=\left\{v_{1}, v_{2}, \ldots, v_{M}\right\}$.

(Rabiner, 1989)

\section{Notation HMM}

Notation used in the HMM are:

$\boldsymbol{T}=$ Number of observations made, usually related to time,

$\boldsymbol{N}=$ Number of hidden state,

$\boldsymbol{M}=$ Number of observed state,

$\boldsymbol{Q}=\left\{q_{1}, q_{2}, \cdots, q_{N}\right\}=$ The set of hidden state,

$\boldsymbol{V}=\left\{v_{1}, v_{2}, \cdots, v_{M}\right\}=$ The set of states that may be observed,

$\boldsymbol{A}=$ Matrix of transition opportunities,

$\boldsymbol{B}=$ Matrix of observation opportunities,

$\boldsymbol{\pi}=$ Matrix of early chances,

$\boldsymbol{O}=\left(O_{1}, O_{2}, \cdots, O_{T}\right)=$ Line of observation,

$\boldsymbol{X}=\left(X_{1}, X_{2}, \cdots, X_{T}\right)=$ Rows hidden state,

(Stamp, 2004)

\section{Viterbi Algorithm}

Viterbi algorithm is used to select the rows of $\mathrm{X}$ are willing hidden state-customized with a maximum $\mathrm{O}$ observations. Viterbi algorithm is a dynamic programming algorithm to find the hidden state sequence dihasil her under observation, especially in the scope of HMM.

Procedure find hidden state ranks up with the Viterbi algorithm formulated as follows

1. Inisialisasi

$$
\delta_{1}(i)=\pi_{i} b_{i}\left(O_{1}\right), 1 \leq i \leq N \text { dan } \psi_{1}(i)=0
$$

2. Rekursif

$$
\begin{array}{r}
\delta_{t}(j)=\max _{1 \leq i \leq N}\left[\delta_{t-1}(i) \cdot a_{i j}\right] b_{j}\left(O_{t}\right) \\
\psi_{t}(j)=\arg \max _{1 \leq i \leq N}\left[\delta_{t-1}(i) \cdot a_{i j}\right], \\
2 \leq t \leq T, 1 \leq j \leq N
\end{array}
$$

Optimal measures currently taken from the previous optimal step. The focus of his is to find rows that have a value of likelihood (probability) maximum. Using likelihood value at the previous step is $\delta_{t-1}(i)$ multiplied by the transition opportunities will be selected maximum value. The maximum value selected multiplied by the chance observation by observation to state $\mathrm{j} t$ namely $\left(O_{t}\right)$ thus obtained likelihood current (current likelihood) are denoted as $\delta_{t}(j)$ the best measure of the state sequence obtained by $\left[\delta_{t-1}(i), a_{i j}\right]$ the maximum argument of which is denoted by $\psi_{t}(j)$.

3. Terminasi

$$
\begin{aligned}
& P^{*}=\max _{1 \leq i \leq N} \delta_{T}(i) \\
& q_{T}^{*}=\arg \max _{1 \leq i \leq N} \delta_{T}(i)
\end{aligned}
$$

4. Backtracking

For $t=T-1, T-2, \ldots, 1$, $q_{t}^{*}=\psi_{t+1}\left(q_{t+1}^{*}\right)$

(Rabiner, 1989)

\section{The Definition of Forex Trading Online}

Forex (foreign exchange) is a type of transaction that traded currency in the currency of a country other State. Forex is a trade involving major financial markets in the world for 24 hours continuously and it is an investment instrument that involves analytical support in achieving a level of profit to the movement of major currencies in the world.

The definition of online forex trading is the trading or foreign currency exchange foreign currency contracts with a single unit called a lot and done online. In the trading market of sellers and buyers are both commonly called the trader (trader).

\section{Online Broker}

Understanding and duties of the Broker is very simple, namely, a party can be a company, individual or agency where he stands or function as an intermediary to bridge or reconcile between the buyer and seller. Forex, gold, silver, index instruments are generally traded.

Forex trading in the common world among the biggest banks in the world. If a trader wants to get into the trade, must have access to or contact with these banks that are in fact very difficult in because of the huge capital requirements. Therefore, the emerging online retail broker that connects traders to banks so they can keep trading with small capital. Online brokers are usually chosen according to kebutuhan individual trader. In addition, the presence of 
these online brokers, may facilitate the traders to transact online. (Jaya, 2012)

\section{METHODS}

\section{Type of Research}

Related to the nature of the data and data analysis techniques are used, this type of research in this study is qualitative and quantitative.

\section{Data Collection}

The data used to build the initial odds matrix (), the matrix of transition opportunities (A) and a chance observation matrix (B) is the quantitative data, in the form of numerical data which is then processed mathematically. To establish state observed in this case used qualitative data, through interviews with respondents and data collection through the media.

The data used in this study in the form of primary data. Primary data is survey data using questionnaires to online forex trader in Indonesia.

\section{Population and Sample}

Prior to sampling, preliminary survey first conducted by distributing questionnaires to 30 online forex trader in Indonesia as a respondent. Of the 30 respondents, only 28 respondents who filled out questionnaires correctly and completely, the proportion of subjects success in completing the questionnaire was thus obtained $\mathrm{p}=0.93 \mathrm{q}=0.07$. Sampling process done by using purposive sampling technique (based on the consideration in accordance with the purpose of research). Samples taken are online forex traders in Indonesia. Determination of the number of respondents was calculated by using the formula:

$$
\begin{aligned}
& n_{0}=\left(\frac{Z \alpha / 2}{d}\right)^{2} p q \\
& n=\frac{n_{0}}{\left(1+\frac{n_{0}}{N}\right)}
\end{aligned}
$$

Description:

$\mathrm{N}=$ total population members

$n_{0}=$ The estimated number of samples

$\mathrm{n}=$ number of samples taken

$\alpha=0.05$ level of confidence

$\mathrm{Z}=$ the value of the normal distribution (for $\alpha=$ 0.05 then $=1.96$ )

$\mathrm{d}=$ a tolerable margin of error in determining the sample mean $=0.05$

$\mathrm{p}$ = proportion of questionnaires were filled in correctly and completely

$\mathrm{q}$ = proportion of questionnaires filled in incorrect and / or incomplete

(Cochran, 1991)
Estimated number of samples are obtained

$$
\begin{aligned}
& n_{0}=\left(\frac{1,96}{0,05}\right)^{2} 0,93 \times 0,07 \\
& n_{0}=100,0353
\end{aligned}
$$

Assumed number of online forex trader in Indonesia is $10 \%$ of the number of Internet users in Indonesia in 2012, that is 80 million people. Thus, the number of online forex trader population is $10 \%$ of 80 million people, which is 8 million people. To obtain the following calculation:

$$
\begin{aligned}
& n=\frac{100,0353}{\left(1+\frac{100,0353}{8000000}\right)} \\
& n=100,0341 \approx 100 \text { responden }
\end{aligned}
$$

From the above calculations, the number of samples taken was 100 respondents.

\section{Interview and Questionnaire}

Before researchers distributed questionnaires to the respondents, the researchers are looking for information to make observations through interviews with respondents or through the media to determine the parameters of observation (observed state).

Furthermore, the researchers spread forex online questionnaires to respondents in Indonesia. Data results of this questionnaire in the form of data transfer broker online forex trader to the period October 2011 to March 2012. Data obtained from the questionnaire will then be processed to get the early opportunity matrix (O), the matrix of transition opportunities (A) and a chance observation matrix (B).

\section{DATA ANALYSIS}

\section{Observed State and Hidden State}

1. Based on research conducted before making the questionnaire, the characteristics of online forex brokers are divided into 5 categories: Leverage up to $1: 1000$, often to invent a unique competition, a 30\% deposit, using the trading platform MetaTrader 4 and 5, the availability of PAMM, profit restrictions during the news.

2. $25 \%$ deposit bonus, up to $1: 500$ leverage, rarely entered the competition, using the trading platform MetaTrader 4, representatives / IB is still a bit in Indonesia.

3. Trading platform is java based, each opening an account will get $\$ 5,1: 500$ leverage, no deposit bonus, there is a chat service on the trading platform, the process of withdrawal of time (up to 1 week).

4. There are many offices in Indonesia, just leverage up to 1:500, rarely hold trading competitions, using the trading platform 
MetaTrader 4 and 5 (for metatrader demo version 5 only accounts only).

5. Leverage up to $1: 200$ only, rarely hold trading competitions, using the trading platform MetaTrader 4 and 5, is listed / regulated in some countries like the U.S. and the UK, the service payment system slightly so that the withdrawal process takes 2-3 days (using a wire transfer) , spread currency pairs traded little changed at any time yet.

Further 5 categories above are components of Hidden Markov Models (HMM) is a state observed in this study. While the hidden state is 5 online forex brokers, that Marketiva, Masterforex, Instaforex, FBS and Others.

\section{Initial Construction Opportunity Matrix ( $\pi$ )}

The data was obtained through a questionnaire grouped by online forex broker is selected in October 2011. The number of respondents who chose each forex broker online divided by the total respondents in October 2011, in order to obtain the initial value, where $\mathrm{i}$ \{Marketiva, Masterforex, Instaforex, FBS and Others\}.

\section{Construction Opportunities Transition Matrix (A)}

The data have been obtained through questionnaires, calculated how much displacement of respondents in the period October 2011 to March 2012 and who continue to use the same online forex broker. This data is set out in tabular form. Each displacement divided by the number of respondents forex broker online in October 2011, found that the transition opportunities later written down in the form of a $5 \times 5$ matrix A. If the matrix A has been obtained, it can be made schemes Hidden Markov models but first do the construction for the matrix observation opportunities.

\section{Opportunity Matrix Construction Observation (B)}

Data obtained through the questionnaire grouped by category selected, then calculated how the number of respondents for each online forex broker in each category, and the number is divided by the number of respondents online forex broker in 2012, found that observation opportunities later written in matrix form B.

\section{Construction Program}

Creating software design using Delphi 7.0 software to search for a maximal series of hidden states using the Viterbi algorithm.

\section{DISCUSSION}

Online Forex Broker is Selected Respondents Based on responses to questionnaires obtained by the number of respondents who use online forex broker in October 2011 as follows:

Table 1. Number of respondents forex broker online in October 2011

\begin{tabular}{|c|l|c|c|}
\hline No & $\begin{array}{c}\text { Broker Forex } \\
\text { Online }\end{array}$ & Responden & Proporsi \\
\hline 1 & Marketiva & 16 & 0,132 \\
\hline 2 & Masterforex & 57 & 0,471 \\
\hline 3 & Instaforex & 30 & 0,248 \\
\hline 4 & FBS & 12 & 0,099 \\
\hline 5 & Others & 6 & 0,050 \\
\hline & Total & $\mathbf{1 2 1}$ & $\mathbf{1}$ \\
\hline
\end{tabular}

Column proportions in Table 1 is obtained by dividing the number of respondents of each forex broker online by the total number of respondents. For example: there are 16 respondents Marketiva divided the total number of respondents 121 then the result obtained is 0.132 .

While the data of respondents who use online forex broker in March 2012 are shown in Table 2 below:

Table 2. Number of respondents forex broker online in March 2012

\begin{tabular}{|c|l|c|c|}
\hline No & $\begin{array}{c}\text { Broker Forex } \\
\text { Online }\end{array}$ & Responden & Proporsi \\
\hline 1 & Marketiva & 20 & 0,165 \\
\hline 2 & Masterforex & 49 & 0,405 \\
\hline 3 & Instaforex & 34 & 0,281 \\
\hline 4 & FBS & 8 & 0,066 \\
\hline 5 & Others & 10 & 0,083 \\
\hline & Total & $\mathbf{1 2 1}$ & $\mathbf{1}$ \\
\hline
\end{tabular}

The number of respondents in each forex broker online is changing. For example: the number of respondents Marketiva

In October 2011 there were 16 respondents, in March 2012 changed to 20 respondents. This change also implies a change in the proportion of each respondent online forex broker. For example: The proportion of respondents Marketiva in October 2011 is 0.132, but in March 2012 the proportion of respondents Marketiva be 0.165 .

The data in Table 1 column matrix of proportions used to construct early chances $\boldsymbol{\pi}=\left\{\pi_{i}\right\}$ that the results presented in Table 3 below:

Table 3. Matrix of Opportunity Beginning $(\pi)$ :

\begin{tabular}{|c|l|c|}
\hline $\begin{array}{c}\text { No } \\
(i)\end{array}$ & $\begin{array}{c}\text { Broker Forex } \\
\text { Online }\left(q_{i}\right)\end{array}$ & $\begin{array}{c}\text { Peluang Awal } \\
\left(\pi_{i}\right)\end{array}$ \\
\hline 1 & Marketiva & 0,132 \\
\hline 2 & Masterforex & 0,471 \\
\hline 3 & Instaforex & 0,248 \\
\hline 4 & FBS & 0,099 \\
\hline 5 & Others & 0,050 \\
\hline & Total & $\mathbf{1}$ \\
\hline
\end{tabular}


Early chances matrix $\pi$ can be written: $\boldsymbol{\pi}=\left[\begin{array}{lllll}0,132 & 0,471 & 0,248 & 0,099 & 0,050\end{array}\right]$

\section{Displacement Trader in Choosing Online Forex Broker}

Processed responses to questionnaires to describe the displacement trader in choosing a forex broker online from October 2011 to March 2012, as shown in Table 4 below:

Table 4. Displacement trader in choosing a forex broker online

\begin{tabular}{|c|c|c|c|c|c|c|}
\hline $\begin{array}{r}\text { Maret } \\
2012\end{array}$ & 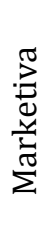 & 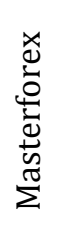 & 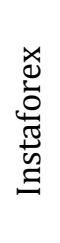 & $\mathscr{p}_{\text {II }}^{n}$ & $\frac{2}{d}$ & \\
\hline Marketiva & 9 & 2 & 2 & 2 & 1 & 16 \\
\hline Masterforex & 5 & 38 & 10 & 3 & 1 & 57 \\
\hline Instaforex & 3 & 3 & 18 & 2 & 4 & 30 \\
\hline FBS & 3 & 4 & 3 & 1 & 1 & 12 \\
\hline Others & 0 & 2 & 1 & 0 & 3 & 6 \\
\hline Total & 20 & 49 & 34 & 8 & 10 & 121 \\
\hline
\end{tabular}

Table 4 can be read: the first line shows traders using Marketiva broker in October 2011 amounted to 16 traders. Then in March 2012, from 16 traders Marketiva is there 9 traders who continue to use the broker Marketiva, 2 traders move to broker Masterforex; 2 traders move to broker Instaforex, 2 traders move to broker FBS, and one trader to move to broker Others. Thus, the data in Table 4 show that the displacement occurs trader of online forex broker online forex broker one to the other of the period from October 2011 to March 2012. For example: the number of traders using Marketiva broker in October 2011 there were 16 traders, while in March 2012 increased to 20 traders.

\section{Opportunity Transition Matrix (A)}

Referring to Table 4 can be formed matrix A transition opportunities below:

\begin{tabular}{|c|c|c|c|c|c|}
\hline & $\begin{array}{l}\text { Broker } \\
\text { bulan }\end{array}$ & $\begin{array}{l}\text { rex or } \\
\text { aret } 2\end{array}$ & & & \\
\hline$[0,563$ & 0,125 & 0,125 & 0,125 & $0,062]$ & \multirow{5}{*}{$\begin{array}{c}\text { Broker forex } \\
\text { online bulan } \\
\text { Oktober } 2011\end{array}$} \\
\hline 0,088 & 0,667 & 0,175 & 0,053 & 0,017 & \\
\hline 0,100 & 0,100 & 0,600 & 0,067 & 0,133 & \\
\hline 0,250 & 0,334 & 0,250 & 0,083 & 0,083 & \\
\hline 0 & 0,334 & 0,166 & 0 & 0,500 & \\
\hline
\end{tabular}

Value entry in the matrix A is obtained by dividing the number of respondents each forex broker online in October 2011 by the total number of respondents each forex broker online in October 2011. For example: the value of 0.563 is obtained by dividing the number of respondents broker Marketiva in October 2011 that as many as nine respondents to the total number of respondents broker Marketiva in October 2011 that as many as 16.
The matrix $A$ is the matrix of transition opportunities to transfer trader online forex broker. For example, a trader the opportunity to move from Masterforex Marketiva is equal to 0.088 , mathematically written

$P($ Marketiva $\mid$ Masterforex $)=0,088$.

\section{Opportunity Observation Matrix (B)}

Options traders on online forex broker in each category based on the data obtained are presented in Table 5 below:

Table 5. Option traders on forex brokers online by category

\begin{tabular}{|l|c|c|c|c|c|c|}
\hline $\begin{array}{l}\text { Krokex } \\
\text { Forex } \\
\text { Online } \\
\text { Maret 2012 }\end{array}$ & $\mathbf{1}$ & $\mathbf{2}$ & $\mathbf{3}$ & $\mathbf{4}$ & $\mathbf{5}$ & Total \\
\hline Marketiva & 1 & 3 & 13 & 2 & 1 & $\mathbf{2 0}$ \\
\hline Masterforex & 6 & 5 & 2 & 33 & 3 & $\mathbf{4 9}$ \\
\hline Instaforex & 26 & 1 & 3 & 2 & 2 & $\mathbf{3 4}$ \\
\hline FBS & 1 & 6 & 1 & 0 & 0 & $\mathbf{8}$ \\
\hline Others & 1 & 1 & 1 & 1 & 6 & $\mathbf{1 0}$ \\
\hline Total & $\mathbf{3 5}$ & $\mathbf{1 6}$ & $\mathbf{2 0}$ & $\mathbf{3 8}$ & $\mathbf{1 2}$ & $\mathbf{1 2 1}$ \\
\hline
\end{tabular}

Table 5 shows the options trader on online forex broker based category, for example: traders who choose a broker Marketiva by category 1 by 1 person, based on category 2 as many as 3 people, based on category 3 as many as 13 people, according to category 4 by 2 people and based on category 5 by 1 person.

Based on Table 5 can be generated matrix observation opportunities (B) the following:

$\boldsymbol{B}=\left[\begin{array}{ccccc}0,050 & 0,150 & 0,650 & 0,100 & 0,050 \\ 0,123 & 0,102 & 0,041 & 0,673 & 0,061 \\ 0,765 & 0,029 & 0,088 & 0,059 & 0,059 \\ 0,125 & 0,750 & 0,125 & 0 & 0 \\ 0,100 & 0,100 & 0,100 & 0,100 & 0,600\end{array}\right] \begin{aligned} & \text { Broker forex } \\ & \text { online bulan } \\ & \text { Maret } 2012\end{aligned}$

Value entry in the matrix $B$ is obtained by dividing the number of respondents of each forex broker online in March 2012 for each category selected by the total number of respondents each forex broker online in March 2012. For example: the value of 0.050 is obtained by dividing the number of respondents broker Marketiva in October 2012 that choosing a category 1sebanyak one respondent to the total number of respondents broker Marketiva in March 2012 that as many as 20 .

The matrix $B$ is a matrix which shows the trader the opportunity to choose a forex broker online by category. For example: if you use a broker Instaforex trader in March 2012, then the chances of traders choose a category 1 is 0.765 , mathematically written $=0.765$. 


\section{Viterbi Algorithm}

Viterbi algorithm is a dynamic programming algorithm to find the hidden state sequence the maximum of a sequence of observations. Source code of the Viterbi algorithm is shown in Table 6 below:

Table 6. Source code Algoritma Viterbi

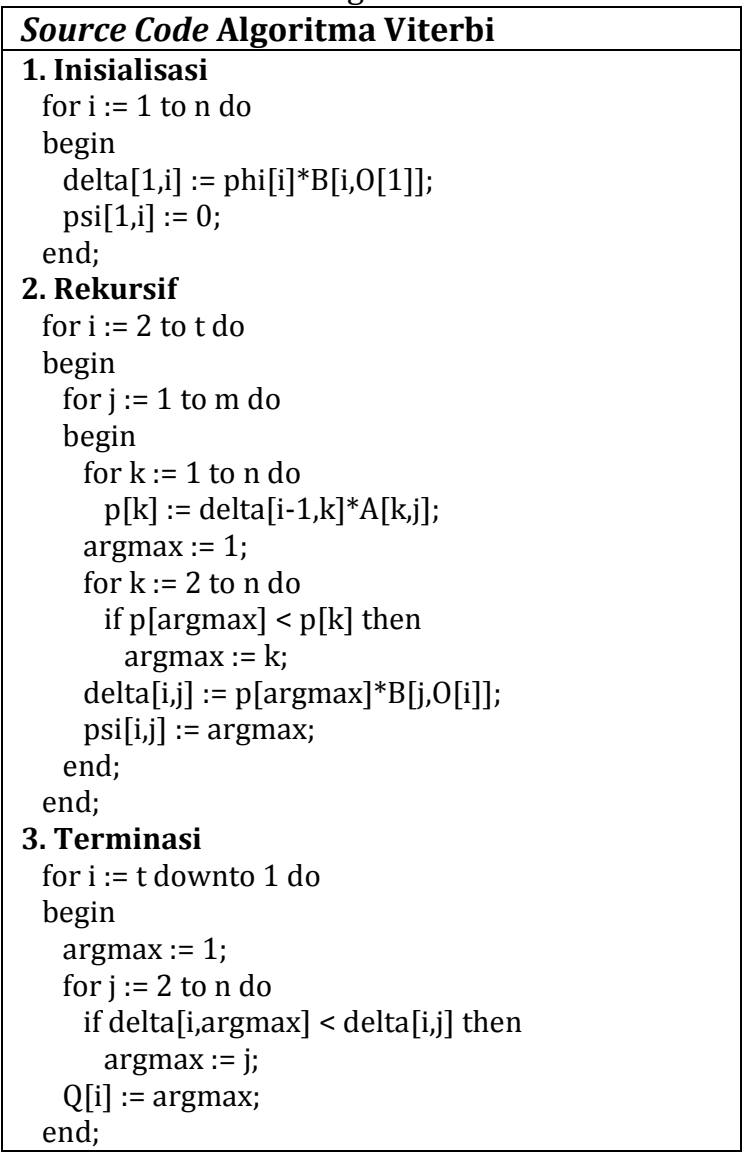

Implementation of hidden markov model in the line forex broker Online

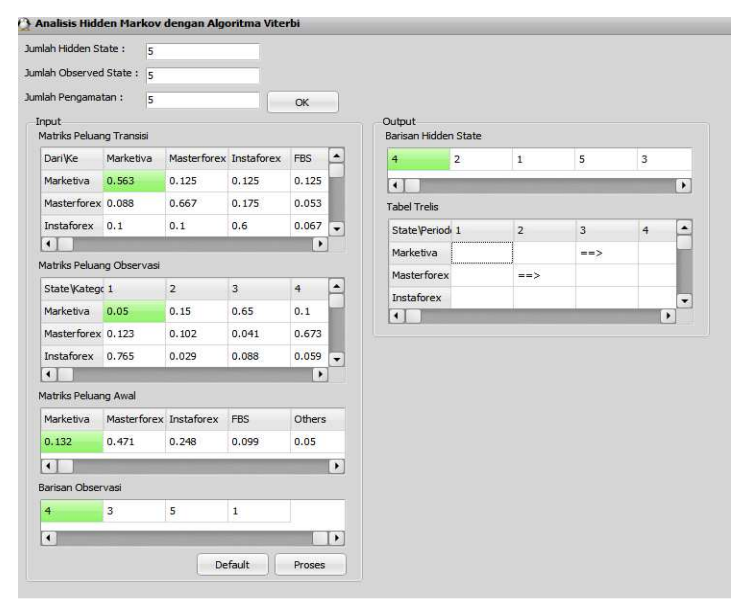

Figure 1. Implementation of hidden markov models for sequence search online forex broker.

Figure 1 shows the output of a program that has been run with the data desired by the transition matrix A and matrix opportunity observation opportunities B and Table 3 for the matrix early chances. For example, the observation sequence used simulated data with the number of observations $\mathrm{T}=5$,

$$
O=\left(O_{1}=2, O_{2}=4, O_{3}=3, O_{4}=5, O_{5}=1\right) \text {. }
$$

Rows of hidden states that best fits the observations 0 are:

$$
X=\left(X_{1}=4, X_{2}=2, X_{3}=1, X_{4}=5, X_{5}=3\right)
$$

Thus the ranks of online forex brokers are:

$\left(X_{1}=\right.$ FBS, $X_{2}=$ Masterforex,$X_{3}=$ Marketiva, $X_{4}=$ Others, $X_{5}=$ Instaforex).

\section{CONCLUSION}

The conclusions obtained are:

1. Hidden Markov Models can be used to find the transfer trader of online forex broker to make the construction of the model through model construction, $\lambda=(\boldsymbol{\pi}, \boldsymbol{A}, \boldsymbol{B})$ earned-right hidden state line that best fits the observation state $\mathrm{O}$. For example: the number of observations $\mathrm{T}=5$ with the line observed state $\mathrm{O}=(2,4,3,5,1)$, be the line most likely hidden state with observed state $\mathrm{O}$ :

$X=\left(X_{1}=4, X_{2}=2, X_{3}=1, X_{4}=5, X_{5}=3\right)$

where $X_{1}=$ FBS, $X_{2}=$ Masterforex,

$\mathrm{X}_{3}=$ Marketiva, $\mathrm{X}_{4}=$ Others, $\mathrm{X}_{5}=$ Instaforex.

2. Applications of Hidden Markov Models has been done by making a program with the Viterbi algorithm in Delphi 7.0 software with state observed form the simulation data.

\section{SUGGESTION}

Further research on online forex brokers can be developed by using the Baum-Welch algorithm that aims to optimize the model parameters in a way to renew (re-estimation) model $\boldsymbol{\lambda}=(\boldsymbol{\pi}, \boldsymbol{A}, \boldsymbol{B})$.

\section{REFERENCES}

[1]. Anonim. 2011.HMM/Model Markov Tersembunyi. http://www.wikipedia.com

[2]. Cochran, W. G. 1991. Teknik Penarikan Sampel. Penerjemah: Rudiansyah. Universitas Indonesia Press. Jakarta.

[3]. Evans, L. C. 2003. An Introduction to Stochastic Differential Equations. Versi 1.2. Departement of Mathematics, UC Berkeley.

[4]. Hidayanto, A. 2009. Teori Umum Rantai Markov. Jurnal. achmad.blog.undip.ac.id.

[5]. Jaya, I. G. T. 2012. Aplikasi Analytic Hierarchy Process untuk Memilih Broker Forex Online. Skripsi. Jurusan Matematika Universitas Brawijaya, Malang. 
[6]. Lestari, Y. D. 2009. Penerapan Model Hidden Markov pada Peramalan Harga Premium. Penelitian. Jurusan Matematika Institut Teknologi Sepuluh November, Surabaya.

[7]. Nugroho, S. 2008. Dasar-dasar Metode Statistika. PT. Grasindo. Jakarta

[8]. Rabiner, L. R. 1989. A Tutorial on Hidden Markov Models and Selected Applications in Speech Recognation. Proceedings of The IEEE, 77 (2), 257-286.

[9]. Stamp, M. 2004. A Revealing Introduction to Hidden Markov Models.
[10]. www.cs.sjsu.edu/faculty/stamp/RUA/HMM. pdf

[11]. Sumarminingsih, E. 2006. Modul Proses Stokastik. Jurusan Matematika FMIPA Universitas Brawijaya, Malang.

[12]. Walpole, R. E. 1995. Pengantar Statistika Edisi Ke-3. PT Gramedia Pustaka Utama, Jakarta 